\title{
The platelet aggregometer
}

\author{
Carlo L. Balduini
}

Ferrata-Storti Foundation, Pavia, Italy

E-mail: carlo.balduini@unipv.it

doi:10.3324/haematol.2021.280198

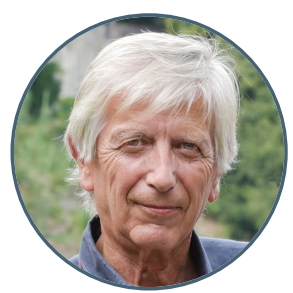

AITLE Aggregation of blood platelets by adenosine diphosphate and its reversal

\section{AUTHORS Gustav Victor Rudolph Born}

JOURNAL Nature. 1962;194:927-929. PMID: 13871375

M ax Schultze identified platelets in 1865 and described them as "small colorless spherules often grouped together". ${ }^{1}$ A few years later, in 1882, Giulio Bizzzero realized that the ability of platelets to cluster at the site of vascular damage is the basis of the hemostatic process. ${ }^{2}$ Although these two fathers of platelets noted that platelets tend to aggregate, the mechanisms of this phenomenon remained mysterious for nearly a century because no technique for studying platelet function was available. The turning point occurred in 1962, when Gustav Born, at that time Professor of Pharmacology at the Royal College of Surgeons of England, published the paper 'Aggregation of blood platelets by adenosine diphosphate and its reversal' in Nature. In this Letter to the Editor, Born described a simple instrument consisting of a photometer that measures the passage of light through a siliconized tube in which platelets are kept in suspension by a rotating magnetic bar. When platelets aggregate, the optical density of the platelet suspension decreases and light transmission increases. In the same article Born reported that ATP and AMP inhibit platelet aggregation and concluded that 'it is conceivable that AMP or some other substance could be used to inhibit or to reverse platelet aggregation in thrombosis'. The idea of antiplatelet agents was born! Being strictly against patenting anything of potential medical value for mankind, Born did not patent his invention that, in a few years, was marketed by more than ten firms and spread to all laboratories interested in hemostasis. It is thanks to the aggregometer that Weiss \& Aledort demonstrated that the intake of aspirin inhibits platelet aggregation, John Vane and his colleagues showed that aspirin is an inhibitor of the prostaglandin-forming cyclooxygenase, and Hamberg \& Samuelsson identified the pro-aggregating substance (now known as) thromboxane A2. Summarizing his work in the field of platelet aggregation, Born wrote "It is gratifying that the feedback hypothesis of platelet aggregation turned out to be explanatory of the remarkable effectiveness of antiplatelet drugs of the aspirin type in the prevention of heart attacks and strokes". There is no doubt that the discovery of antiplatelet agents is one of the most remarkable achievements of pharmacological research of the twentieth century. Moreover, it should not be forgotten that the identification of numerous hemorrhagic diseases due to a functional platelet defect is largely due to Born's aggregometer, which is still in use in most clinical and research laboratories concerned with thrombosis and hemostasis. The great fame derived from the aggregometer must not make us forget the many other scientific merits of Born, including important studies on atherosclerotic plaques, pioneering use of intravital microscopy and direct recording of white blood cell behavior in small vessels. For his achievements Born received honorary $\mathrm{MD}$ or DSci degrees from ten European and US universities, and the Centre for Vascular Research at the University of Edinburgh was named after him.

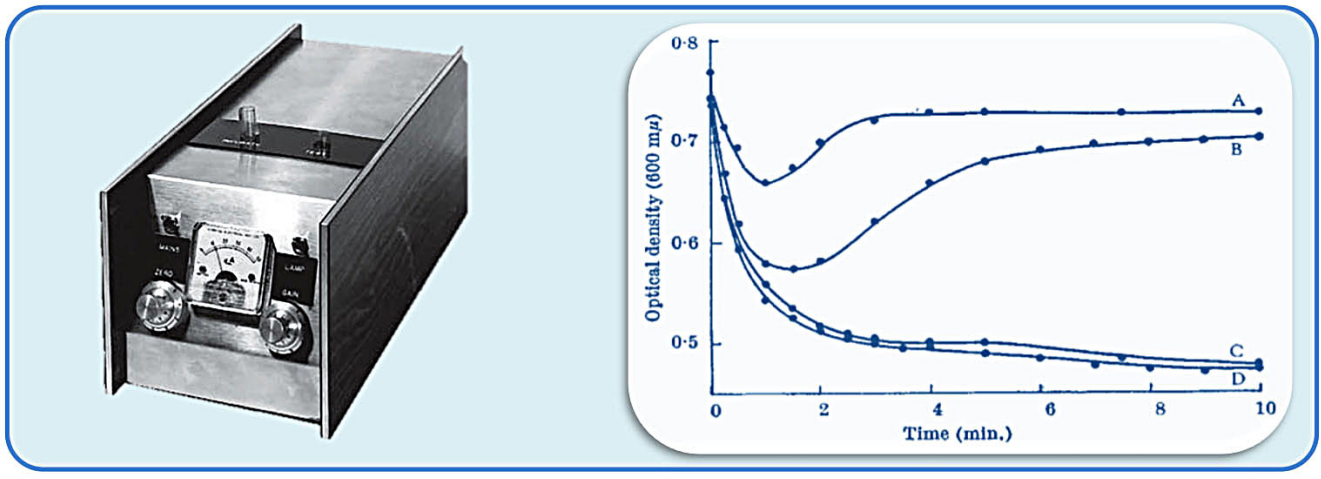

Born's platelet aggregometer. (A) The first aggregometer produced by Born in the workshop of the Royal College of Surgeons in London. (B) Tracings of platelet aggregation from the paper published in Nature in 1962. The addition of ADP to platelet-rich plasma causes a reduction in the latter's optical density which is proportional to the extent of platelet aggregation. With low doses of ADP the aggregation is reversible, while with higher doses it becomes irreversible (Reproduced from Nature, with permission).

\section{References}

1. Schultze, M. Ein heizbarer Objecttisch und seine Verwendungbei Untersuchungen des Blutes. Archiv für mikroscopische Anatomie. 1865;1:1-42.

2. Bizzozero, J. Ueber einen neuen Formbestandtheil des Blutes und dessen Rolle bei der Thrombose und der Blutgerinnung. Archiv für Pathologische Anatomie und Physiologie und für klinische Medicin 1882;90:261-332. 